\title{
Deposition and Thermal Stability of DLC/Si-N Composite Films Synthesized Using a Sputtering-PBII Hybrid System
}

\author{
Anas Mohammed A. Melih ${ }^{1 *}$, Keita Yamada ${ }^{1}$, Shuichi Watanabe ${ }^{2}$ \\ ${ }^{1}$ Mechanical Systems Engineering Major, Graduate School of Engineering, Nippon Institute of Technology, Saitama, Japan \\ ${ }^{2}$ Department of Applied Chemistry, Faculty of Fundamental Engineering, Nippon Institute of Technology, Saitama, Japan \\ Email: *anasmelih525@hotmail.com
}

How to cite this paper: Melih, A.M.A., Yamada, K. and Watanabe, S. (2019) Deposition and Thermal Stability of DLC/Si-N Composite Films Synthesized Using a Sputtering-PBII Hybrid System. Materials Sciences and Applications, 10, 746-755. https://doi.org/10.4236/msa.2019.1012054

Received: October 28, 2019

Accepted: December 3, 2019

Published: December 6, 2019

Copyright () 2019 by author(s) and Scientific Research Publishing Inc. This work is licensed under the Creative Commons Attribution International License (CC BY 4.0).

http://creativecommons.org/licenses/by/4.0/ C) (i) Open Access

\begin{abstract}
Diamond-like carbon (DLC) is a metastable amorphous material that exhibits unique properties. However, there are many limitations regarding the use of this material due to factors such as its tribological characteristics at high temperature and limited thermal stability. In this study, the thermal stability and tribological properties of DLC/silicon-nitrogen (DLC/Si-N) composite films were investigated and compared to those of pure DLC films. All the films were synthesized using a combination of radio frequency (RF) magnetron sputtering and plasma-based ion implantation (PBII) (a so-called sputtering-PBII hybrid system) which is newly developed by us. A high purity silicon nitride (99.9\%) disk was used as the target, applying an RF power in the range of $500-700 \mathrm{~W}$ and a negative pulsed bias voltage of $5 \mathrm{kV}$ to the substrate. An Ar- $-\mathrm{CH}_{4}$ mixture was used as the reactive gas. The $\mathrm{CH}_{4}$ partial pressure was varied between 0 and $0.15 \mathrm{~Pa}$, while the total gas pressure and total gas flow were fixed at $0.30 \mathrm{~Pa}$ and $30 \mathrm{sccm}$, respectively. The structures of the resulting films were characterized using Raman spectroscopy, while the thermal stabilities were assessed using thermogravimetric-differential thermal analysis (TG-DTA) and friction coefficients were obtained via ball-on-disk friction tests. The results indicate that the DLC/Si-N composite films produced in this work exhibit improved thermal stability relative to that of pure DLC owing to the presence of thermally stable atomic-scale Si-N compound in the carbon main flame networks. A DLC/Si-N film containing approximately 11 at.\% $\mathrm{Si}$ and 18.5 at.\%N shows good thermal stability in air over $800^{\circ} \mathrm{C}$ up to $1100^{\circ} \mathrm{C}$, together with excellent tribological performance at $500^{\circ} \mathrm{C}$ in air. Overall, the data demonstrate that DLC/Si-N composite films offer improved thermal stability and superior tribological performance at high temperatures.
\end{abstract}




\section{Keywords}

Diamond-Like Carbon, DLC/Si-N, Tribology, Sputtering-PBII Hybrid System

\section{Introduction}

There have been many attempts to develop hard, heat-resistant, low friction thin films that can be used at high temperatures and under high loads. Among the potential candidates, diamond-like carbon (DLC) films exhibit excellent tribological properties, such as a high degree of hardness, low friction, good wear resistance, and low aggressiveness [1] [2]. Other helpful characteristics of these films include chemical stability and tunable electric resistance [3] [4] [5] [6] [7]. As a result, these materials have applications including cutting tools and metal molds. However, depending on the usage environment, there are still challenges such as adhesion to the substrate and limited friction durability, especially at temperatures above $300^{\circ} \mathrm{C}$ [8] [9] [10] [11], and DLC-composite films have been developed as a means of addressing these issues. The incorporation of silicon into DLC has overcome some of the stated drawbacks, including significantly reduced residual stress, while retaining the hardness, improving the thermal stability and delivering a low friction coefficient that is highly insensitive to changes in humidity [12] [13] [14]. When both silicon and oxygen are incorporated into DLC films, significant structural modifications occur. Other authors claim to have obtained a material that consists of an atomic-scale composite of random networks of carbon and silicon in which the carbon network is stabilized by hydrogen, while the silicon network is stabilized by oxygen. This type of structure is referred to as a diamond-like nanocomposite (DLN) [15] [16] [17]. The co-incorporation of silicon/oxygen into DLC films presents interesting mechanical, tribological and optical properties, as well as higher values of thermal stability and fracture toughness [18]. Further, Chen et al. reported that nitrogen-incorporated DLC films were extremely wear resistant with a low coefficient of friction [19]. The reduction in residual stress and the enhancement in thermal stability of nitrogen-incorporated DLC films were previously reported [20] [21] [22]. In our previous study [23], it was found that the silicon/nitrogen co-incorporated DLC films fabricated by PBII using acetylene $\left(\mathrm{C}_{2} \mathrm{H}_{2}\right)$, tetramethylsilane (TMS, $\left.\mathrm{Si}\left(\mathrm{CH}_{3}\right)_{4}\right)$ and nitrogen $\left(\mathrm{N}_{2}\right)$ as plasma sources showed the good thermal stability under a temperature environment of about $600^{\circ} \mathrm{C}$ that has never been reported before. However, it is of interest to develop DLC films that can achieve thermal stability in the region exceeding this temperature.

In the present study, a DLC film was combined with the thermally stable Si-N system [24] [25] to improve more the heat resistance of the original film. A sputtering-plasma based ion implantation (PBII) hybrid process developed in our laboratory [26] was employed in conjunction with $\mathrm{Si}_{3} \mathrm{~N}_{4}$ to prepare DLC/Si-N composite films, and the heat resistance and other properties of these films were assessed. 


\section{Experimental}

Figure 1 shows a schematic diagram of the equipment used in this work. The experimental device contained a substrate holder for use during the PBII process attached at the top and connected to DC pulse and radio frequency (RF) power supplies. The conditions for the fabrication of the film are presented in Table 1. To ensure adhesion of the film to the substrate, the film was subjected to an $\mathrm{Ar}$ ion bombardment for $10 \mathrm{~min}$ as a pretreatment. Following this, $\mathrm{CH}_{4}$ was introduced at approximately $1 \mathrm{~Pa}$, a pulsed $-20 \mathrm{KV}$ DC bias was applied and PBII was carried out for $1 \mathrm{~h}$.

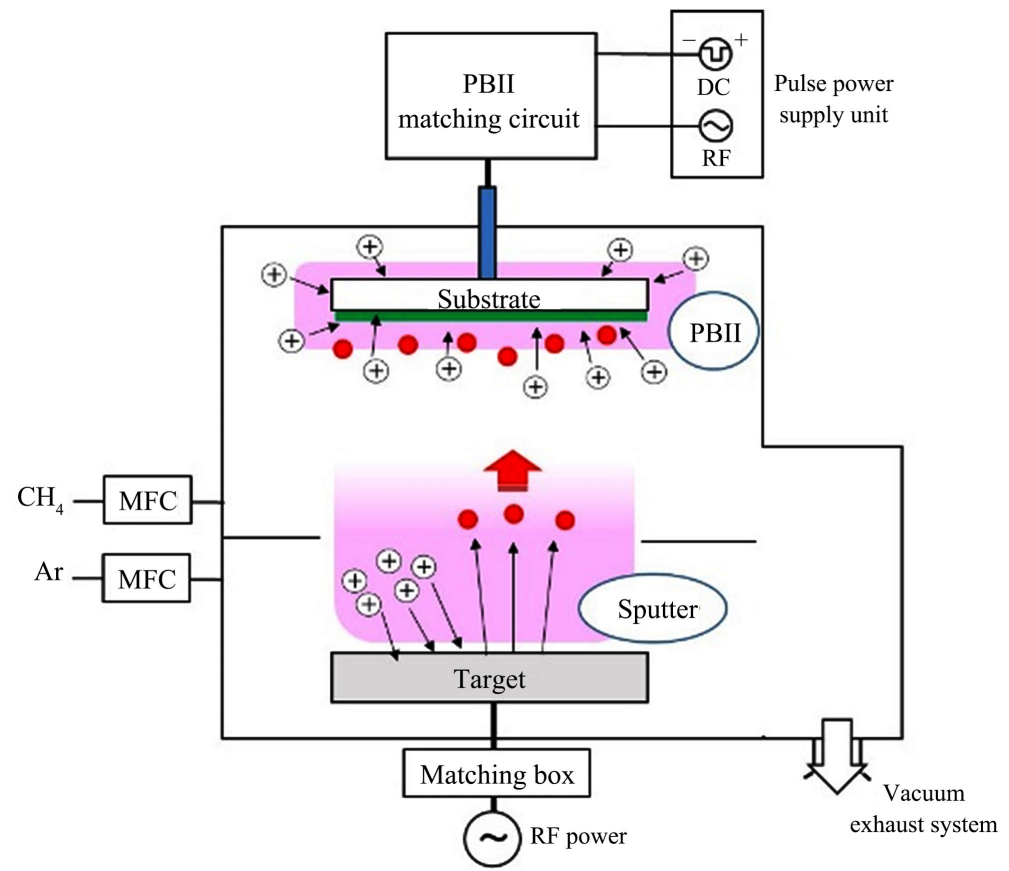

Figure 1. Schematic illustration of Sputtering-PBII Hybrid System used in this experiment.

Table 1. Deposition conditions.

\begin{tabular}{cc}
\hline [Sputtering] & \\
\hline Target & $\mathrm{Si}_{3} \mathrm{~N}_{4}$ \\
RF Power & $500 / 700 \mathrm{~W}$ \\
Target-Substrate Distance & $85 \mathrm{~mm}$ \\
\hline [PBII $]$ & \\
\hline Pulse Frequency & $1.0 \mathrm{kHz}$ \\
DC Pulse Bias & $-5.0 \mathrm{kV}($ Width: $5 \mu \mathrm{s}$, Delay: $25 \mu \mathrm{s})$ \\
Pulse RF Power & $300 \mathrm{~W}(\mathrm{Width}: 50 \mu \mathrm{s}$, Delay: $25 \mathrm{~ns})$ \\
Ar Gas Flow Rate & $30 \mathrm{sccm}$ \\
CH $\mathrm{H}_{4}$ Gas Flow Rate & $10,15,20 \mathrm{sccm}$ \\
Deposition Time & $120 \mathrm{~min}$ \\
\hline
\end{tabular}


The compositions of the resulting films were quantitatively assessed using energy dispersive X-ray spectroscopy (EDS: JSM-IT 300), with a $600 \mathrm{~s}$ analysis at a $15.0 \mathrm{kV}$ acceleration voltage and $10 \mathrm{~mm}$ working distance. The heat resistance of each film was determined using thermogravimetric analysis-differential thermal analysis (TG-DTA). Each film was first formed on aluminum foil and then isolated by dissolving the foil in an aqueous hydrochloric acid solution. During the TG-DTA trials, the specimen was heated to $800^{\circ} \mathrm{C}$ (or as high as $1100^{\circ} \mathrm{C}$ in some cases) in air. The residue deposited in the crucible after the thermal test was then analyzed by EDS using similar instrumental parameters to those described above.

Samples that exhibited minimal mass loss during the TG-DTA investigations were used for friction assessments, which were performed with a ball-on-disk type friction test apparatus. In preparation for these analyses, each film was formed on a superhard material (WC-Co) under the same conditions used to produce the original films, and heat-treated at $500^{\circ} \mathrm{C}$ for $30 \mathrm{~min}$ in an electric furnace prior to the friction test. The friction analysis was conducted using a load of $1 \mathrm{~N}$, a rotation rate of $100 \mathrm{rpm}$, a total of 6000 rotations (or laps), a $3 \mathrm{~mm}$ radius of rotation under air and with an $\mathrm{Al}_{2} \mathrm{O}_{3}$ ball $(\varnothing 6 \mathrm{~mm})$. The vibration friction wear tester called SRV (Schwingungs Reihungund und Verschleiss) tester, which is used as a tester for evaluating tribocoating in fields such as the automobile industry. The samples used for the evaluation were those in which a film was formed on superhard material $(\mathrm{WC}-\mathrm{Co})$ substrate $(12 \times 12 \times 5)$ with a polished surface under the three types of film-forming conditions that were found to have excellent heat resistance in the previous report. The friction test conditions Load $10 \mathrm{~N}$, vibration width $50 \mu \mathrm{m}$, frequency $50 \mathrm{~Hz}$, test time 600 seconds. The sample temperature was set to $200^{\circ} \mathrm{C}$ in consideration of the application field. The structure of the films was analyzed using Raman spectroscopy (JASCO NRS-1000 DT) at an excitation wavelength of $532 \mathrm{~nm}$ and a spot size of $4 \mu \mathrm{m}$. The Raman spectra in the wave number region were deconvoluted from $1000-1800 \mathrm{~cm}^{-1}$ into the Gaussian D and G peaks. The integral area under the D and G peaks was determined by curve fitting.

\section{Results and Discussion}

The films employed in this work were generated using graphite as the target material. The TG data showing mass changes as functions of temperature for both the DLC/Si-N composite and pure DLC films are shown in Figure 2. Sample $1(700 \mathrm{~W}, 10 \mathrm{sccm})$ underwent a large mass loss between $300^{\circ} \mathrm{C}$ and $550^{\circ} \mathrm{C}$ and was completely oxidized at $800^{\circ} \mathrm{C}$, with no residue left after the test. In contrast, samples $2(700 \mathrm{~W}, 15 \mathrm{sccm}), 3(500 \mathrm{~W}, 10 \mathrm{sccm})$ and 4 were found to be stable up to $800^{\circ} \mathrm{C}$, such that only a small mass loss was observed. However, when these same specimens were heated to $1100^{\circ} \mathrm{C}$, samples 3 and 4 demonstrated a significant mass loss, while sample 2 underwent only a small mass loss. The DTA data showed that each of samples 3 and 4 also produced a broad exothermic peak between $700^{\circ} \mathrm{C}$ and $900^{\circ} \mathrm{C}$ (data not shown), which can be attri- 
buted to the combustion of the films. Sample 2 did not generate an exothermic peak above $600^{\circ} \mathrm{C}$, indicating excellent heat resistance.

Prior to the TG-DTA analyses, sample 2 (which demonstrated superior heat resistance), was heated at $800^{\circ} \mathrm{C}$ and $1100^{\circ} \mathrm{C}$, and the changes in the composition of the film residue left in the crucible at both temperatures are graphed in Figure 3. Following heating at $1100^{\circ} \mathrm{C}$, the residue had a lower $\mathrm{C}$ concentration compared to that before the test. However, the reduction in $\mathrm{C}$ content was only approximately $50 \%$ despite the high temperature that was applied. The $\mathrm{O}$ content was found to be as low as $11.3 \%$, confirming relatively minimal oxidation. The residues recovered after heating at $800^{\circ} \mathrm{C}$ and $1100^{\circ} \mathrm{C}$ also showed very similar compositions, demonstrating that sample 2 had good heat resistance.

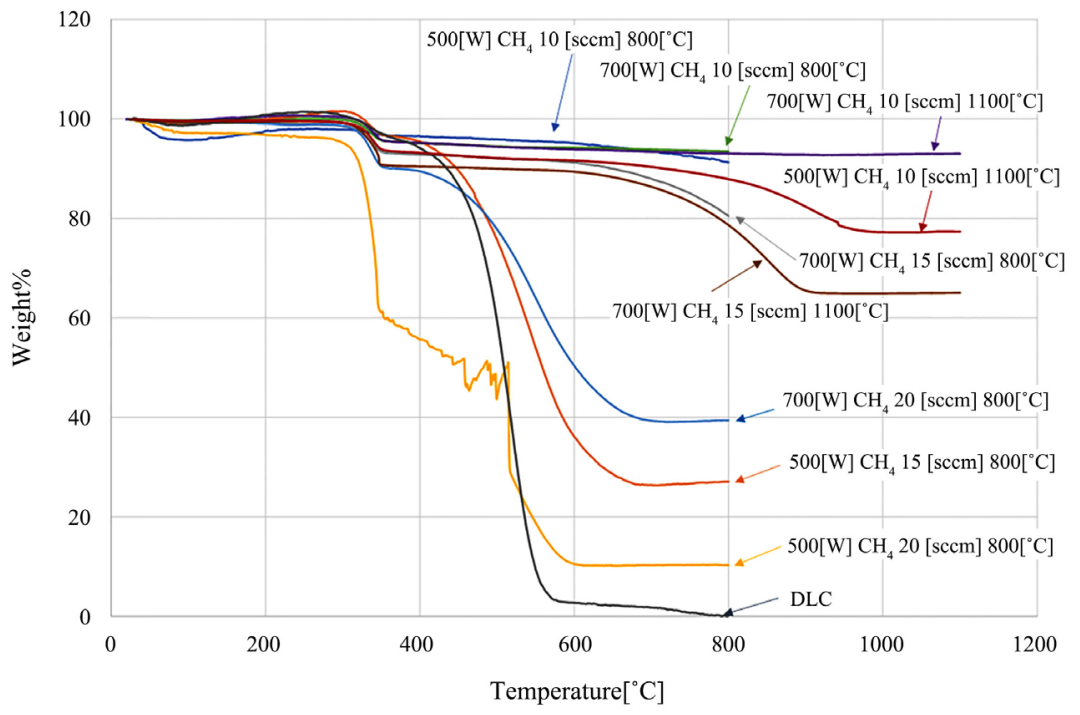

Figure 2. Changes in thermogravimetric curves of the films.

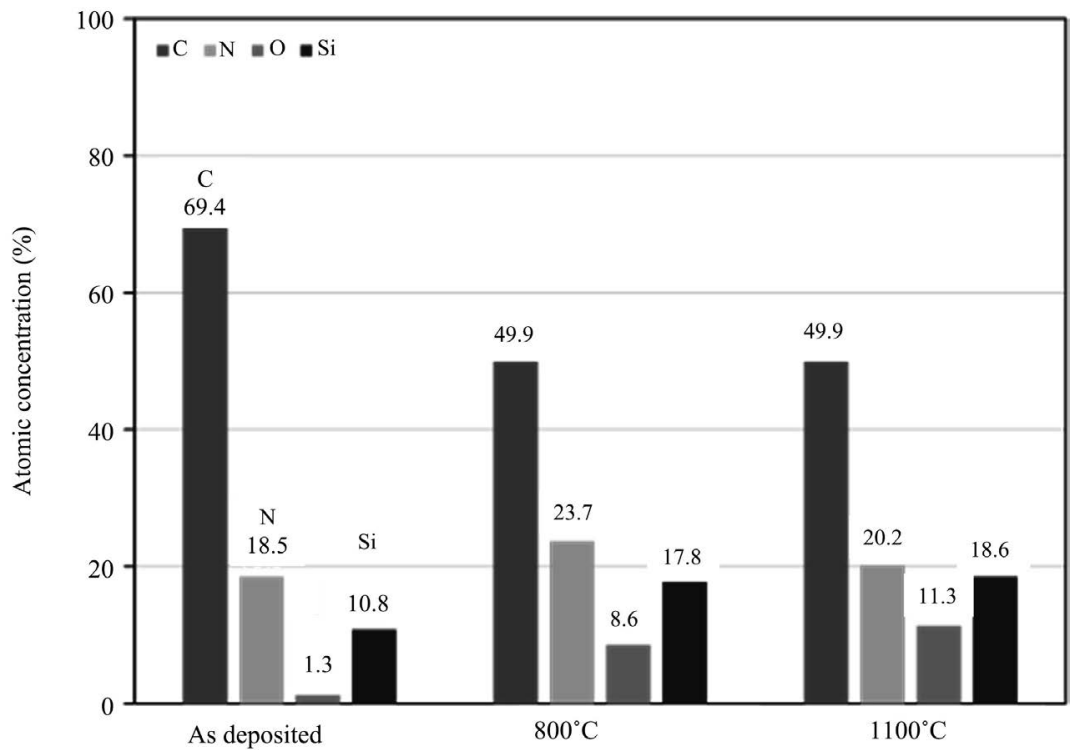

Figure 3. EDS analytical results of as deposited, after $800^{\circ} \mathrm{C}$ heating and after $1100^{\circ} \mathrm{C}$ heating in $700[\mathrm{~W}] \mathrm{CH}_{4} 10[\mathrm{sccm}]$. 
Figure 4 shows the ball-on-disk friction test results for samples 2, 3 and 4, and demonstrates that all three films had relatively low friction coefficients in the range of $0.1-0.3$. However, the friction coefficient for sample 3 was the lowest.

Figure 5 shows the friction test results obtained from films after heating at $500^{\circ} \mathrm{C}$. Here, sample 4 is seen to have had a much higher friction coefficient after heating compared to the value immediately following fabrication. In contrast, the friction coefficients of samples 2 and 3 were more stable, and actually decreased from their original values. The friction coefficient for sample 3 increased to approximately 0.6 during the initial stage of the test, and this effect is attributed to the change in the composition of the material close to the film surface, due to oxidation from heating. This oxidation resulted in a film structure that was easily worn off when heat was applied. As this layer was worn away, the underlying layers that were not affected by heating became the test surface, leading to less friction.

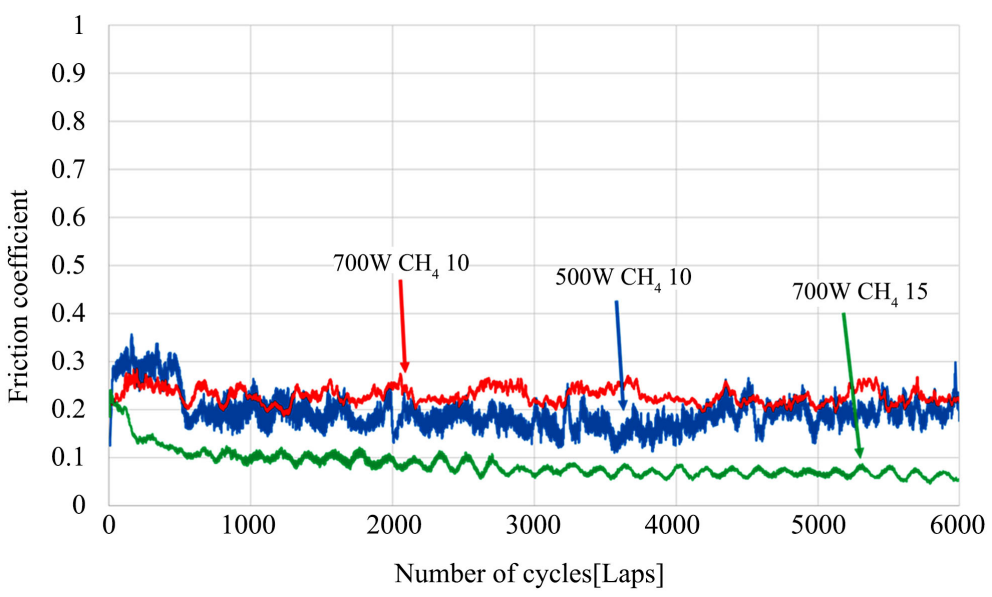

Figure 4. Changes in friction coefficients of three kinds of films at room temperature.

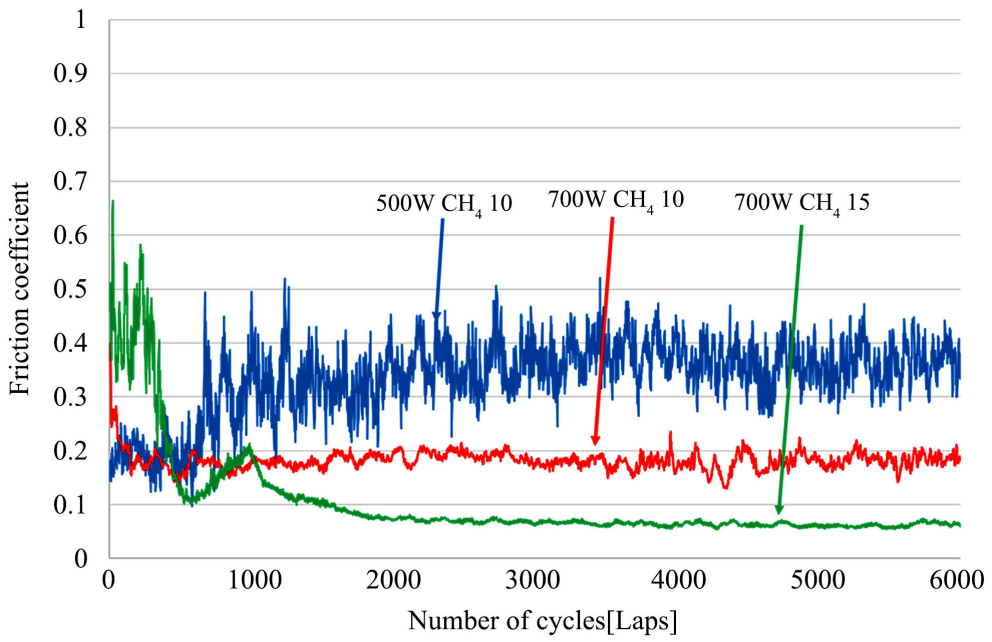

Figure 5. Changes in friction coefficients of three kinds of films after heating of $500^{\circ} \mathrm{C}$. 
Figure 6 shows the change of the friction coefficient with respect to the number of friction of each sample. Although the friction test was repeated three times, the reproducibility was good. Sample 3 had good heat resistance, but the friction coefficient was high and wear was also observed in the ball-on-disk friction test conducted separately, but this was also the case in this SRV test. The film surface was damaged during the test. In comparison, both the samples 1 and 2 showed stable friction behavior in this evaluation, and although there was a difference in the coefficient of friction, no damage was found on the film surface side.

It was confirmed that it was excellent in wear resistance. The friction coefficient of sample 1 is about $0.2-0.25$, which is higher than that of sample 2 , but this tendency was the same in the ball-on-disk test.

Figure 7 shows the Raman spectroscopic results of samples 1 . In the fig, spectra at room temperature, $800^{\circ} \mathrm{C}$ and $1100^{\circ} \mathrm{C}$ are also shown for comparison. From this result, a broad peak composed of D-Band and G-Band, which is common in all DLC films, is confirmed in all films. The as-deposited film shows the Raman spectrum found in typical DLC films. On the other hand, after heating at $800^{\circ} \mathrm{C}$ the peak is broad. In previous studies, there were no reports that two bands of D and G were observed even when the DLC film heated at $800^{\circ} \mathrm{C}$. After heating at $1100^{\circ} \mathrm{C}$, it was found that $\mathrm{D}$ and G-band peak show splitting and G-band peak position shifting to the lower wavenumber side compared to DLC. The changes in these spectra might correlate with graphitization of amorphous carbon (graphite-like spectral shape). As described above, it was confirmed that the carbon network of the DLC film exists without breaking even at a high temperature of $1100^{\circ} \mathrm{C}$.

\section{Conclusion}

DLC/Si-N composite films were formed by adding the thermally stable compounds Si and N to DLC films, so as to enhance the heat resistance of the films.

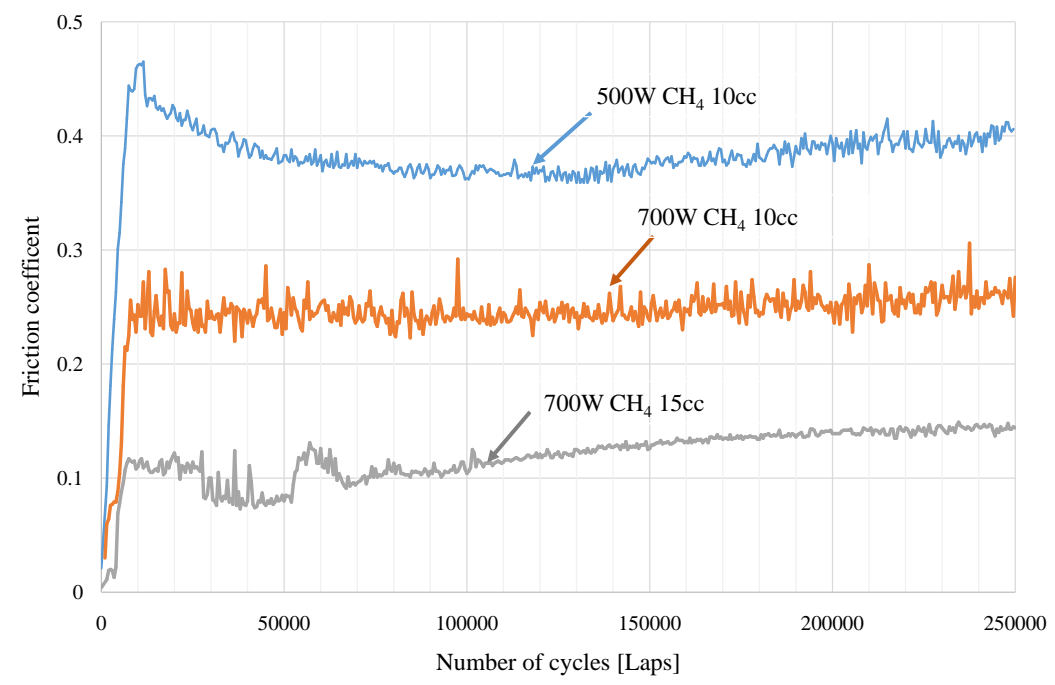

Figure 6. Vibration friction and wear tester SRV evaluation. 


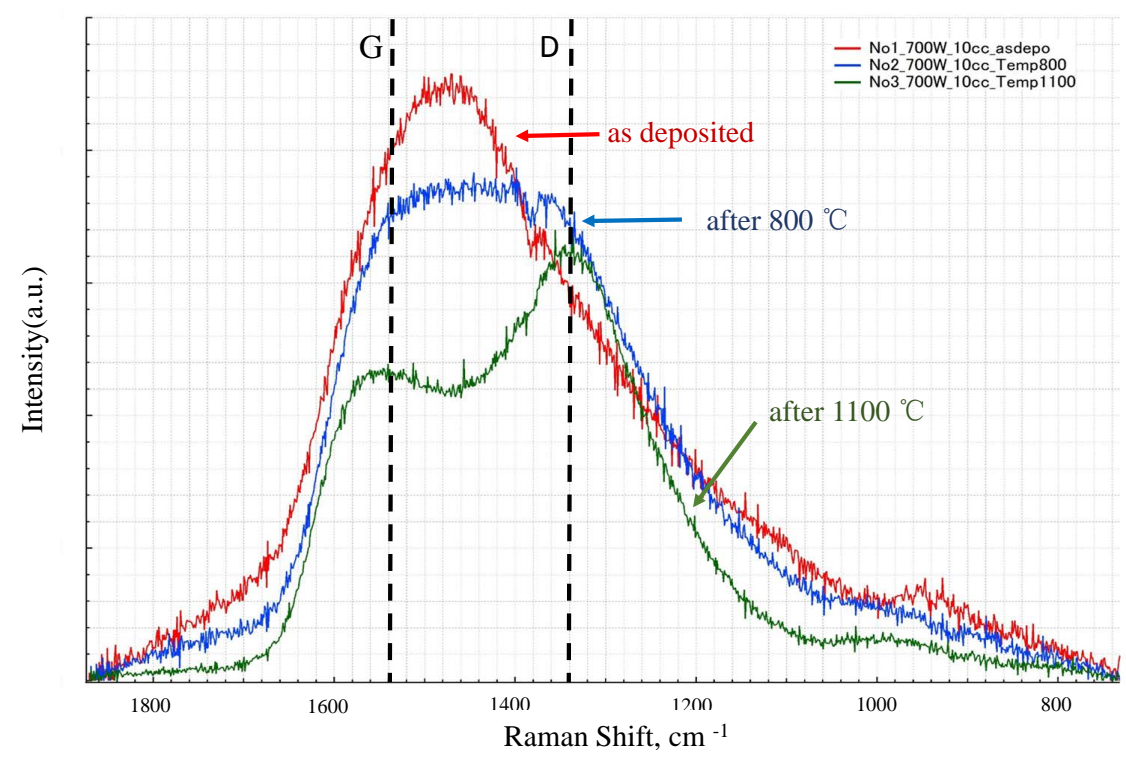

Figure 7. Results of Raman spectroscopy as deposited, after $800^{\circ} \mathrm{C}$ heating and after $1100^{\circ} \mathrm{C}$ heating in $700[\mathrm{~W}] \mathrm{CH}_{4} 10[\mathrm{sccm}]$.

TG-DTA data showed that the heat resistance of the DLC/Si-N composite films was superior to that of a pure DLC film. In particular, the film formed at an RF sputtering power of $700 \mathrm{~W}$ and a $\mathrm{CH}_{4}$ flow rate of $10 \mathrm{sccm}$ exhibited excellent heat resistance together with a minimal mass loss at temperatures as high as $1100^{\circ} \mathrm{C}$. This same film retained as much as $49.9 \% \mathrm{C}$ with an $\mathrm{O}$ content as low as $11.3 \%$, even after heating at $1100^{\circ} \mathrm{C}$. There was no significant change in these values compared to the composition obtained after heating at $800^{\circ} \mathrm{C}$. Ball-on-disk frictional wear tests showed that the coefficient of friction of an optimized film was unchanged by heating to $500^{\circ} \mathrm{C}$ and Tribological properties of DLC/Si-N films with good heat resistance were evaluated using an SRV vibration friction wear tester in consideration of practical application. As a result, it was confirmed that the film with excellent heat resistance also has good wear resistance, because the results indicate that the DLC/Si-N composite films produced in this work exhibit improved thermal stability relative to that of pure DLC owing to the presence of thermally stable atomic-scale Si-N compound in the carbon main flame networks.

\section{Conflicts of Interest}

The authors declare no conflicts of interest regarding the publication of this paper.

\section{References}

[1] Robertson, J. (2002) Diamond-Like Amorphous Carbon. Materials Science and Engineering: R: Reports, 37, 129-281. https://doi.org/10.1016/S0927-796X(02)00005-0

[2] Ferrari, A.C. and Robertson, J. (2000) Interpretation of Raman Spectra of Disordered and Amorphous Carbon. Physical Review B (Condensed Matter and Mate- 
rials Physics), 61, 14095-14107. https://doi.org/10.1103/PhysRevB.61.14095

[3] Vandevelde, T.C.S., Vandierendonck, K., Van Stappen, M., Du Mong, W. and Perremans, P. (1999) Cutting Applications of DLC, Hard Carbon and Diamond Films. Surface and Coatings Technology, 113, 80-85.

https://doi.org/10.1016/S0257-8972(98)00831-7

[4] Hanyu, H.H., Kamiya, S., Murakami, Y. and Kondoh, Y. (2005) The Improvement of Cutting Performance in Semi-Dry Condition by the Combination of DLC Coating and CVD Smooth. Surface Diamond Coating Surface and Coatings Technology, 200, 1137-1141. https://doi.org/10.1016/j.surfcoat.2005.02.022

[5] Dos Santos, G.R., da Costa, D.D., Amorim, F.L. and Torres, R.D. (2007) Characterization of DLC Thin Film and Evaluation of Machining Forces Using Coated Inserts in Turning of Al-Si Alloys. Surface and Coatings Technology, 202, 1029-1033. https://doi.org/10.1016/j.surfcoat.2007.07.100

[6] Bhowmick, S., Banerji, A. and Alpas, A.T. (2015) Tribological Behavior of Al-6.5\%, $-12 \%,-18.5 \%$ Si Alloys during Machining Using CVD Diamond and DLC Coated Tools. Surface and Coatings Technology, 284, 353-364.

https://doi.org/10.1016/j.surfcoat.2015.08.073

[7] Dai, M., Zhou, K., Yuan, Z., Ding, Q. and Zhi, Q. (2000) The Cutting Performance of Diamond and DLC-Coated Cutting Tools. Diamond and Related Materials, 9, 1753-1557. https://doi.org/10.1016/S0925-9635(00)00296-X

[8] Zhang, S., Bui, X.L. and Li, X.M. (2006) Thermal Stability and Oxidation Properties of Magnetron Sputtered Diamond-Like Carbon and Its Nanocomposite Coatings. Diamond and Related Materials, 15, 972-976.

https://doi.org/10.1016/j.diamond.2005.12.005

[9] Vanhulsel, A., Blanpain, B., Celis, J.-P., Roos, J., Dekempeneer, E. and Smeets, J. (1998) Study of the Wear Behaviour of Diamond-Like Coatings at Elevated Temperatures. Surface and Coatings Technology, 98, 1047-1052. https://doi.org/10.1016/S0257-8972(97)00227-2

[10] Gassner, G., Mayrhofera, P.H., Patscheider, J. and Mitterer, C. (2007) Thermal Stability of Nanocomposite CrC/a-C:H Thin Films. Thin Solid Films, 515, 5411-5417. https://doi.org/10.1016/j.tsf.2006.12.149

[11] Deng, X., Kousaka, H., Tokoroyama, T. and Umehara, N. (2014) Tribological Behavior of Tetrahedral Amorphous Carbon (ta-C) Coatings at Elevated Temperatures. Tribology International, 75, 98-103. https://doi.org/10.1016/j.triboint.2014.04.002

[12] Camargo Jr., S.S., Baia Neto, A.L., Santos, R.A., Freire, F.L., Carius, R. and Finger, F. (1998) Improved High-Temperature Stability of Si Incorporated a-C:H Films. Diamond and Related Materials, 7, 1155-1162. https://doi.org/10.1016/S0925-9635(98)00165-4

[13] Baia Neto, A.L., Santos, R.A., Freire Jr., F.L., Camargo Jr., S.S., Carius, R., Finger, F. and Beyer, W. (1997) Relation between Mechanical and Structural Properties of Silicon-Incorporated Hard a-C:H Films. Thin Solid Films, 293, 206-211. https://doi.org/10.1016/S0040-6090(96)08948-1

[14] Oguri, K. and Arai, T. (1992) Friction Coefficient of Si-C, Ti-C and Ge-C Coatings with Excess Carbon Formed by Plasma-Assisted Chemical Vapour Deposition. Thin Solid Films, 208, 158-160. https://doi.org/10.1016/0040-6090(92)90635-O

[15] Dorfman, V.F. (1992) Diamond-Like Nanocomposites (DLN). Thin Solid Films, 212, 267-273. https://doi.org/10.1016/0040-6090(92)90532-G

[16] Kester, D.J., Brodbeck, C.L., Singer, I.L. and Kyria-Kopoulos, A. (1999) Sliding Wear Behavior of Diamond-Like Nanocomposite Coatings. Surface and Coatings 
Technology, 113, 268-273. https://doi.org/10.1016/S0257-8972(99)00003-1

[17] Neerinck, D., Persoone, P., Sercu, M., Goel, A., Kester, D. and Bray, D. (1998) Diamond-Like Nanocomposite Coatings (a-C:H/a-Si:O) for Tribological Applications. Diamond and Related Materials, 7, 468-471. https://doi.org/10.1016/S0925-9635(97)00201-X

[18] Yang, W.J., Sekino, T., Shim, K.B., Niihara, K. and Auh, K.H. (2005) Microstructure and Tribological Properties of SiOx/DLC Films Grown by PECVD. Surface and Coatings Technology, 194, 128-135. https://doi.org/10.1016/j.surfcoat.2004.05.023

[19] Chen, M.Y., Lin, X., Dravid, V.P., Chung, Y.W., Wong, M.S. and Sproul, W.D. (1992) Growth and Characterization of C-N Thin Films. Surface and Coatings Technology, 54-55, 360-364. https://doi.org/10.1016/S0257-8972(07)80048-X

[20] Bai, H.L. and Jiang, E.Y. (1999) Improvement of the Thermal Stability of Amorphous Carbon Films by Incorporation of Nitrogen. Thin Solid Films, 353, 157-165. https://doi.org/10.1016/S0040-6090(99)00421-6

[21] Franceschini, D.F., Acheter, C.A. and Freire, F.L. (1992) Internal Stress Reduction by Nitrogen Incorporation in Hard Amorphous Carbon Thin Films. Applied Physics Letters, 60, 3229-3231. https://doi.org/10.1063/1.106702

[22] Konkhunthot, N., Photongkam, P. and Wongpanya, P. (2019) Improvement of Thermal Stability, Adhesion Strength and Corrosion Performance of Diamond-Like Carbon Films with Titanium Doping. Applied Surface Science, 469, 471-486. https://doi.org/10.1016/j.apsusc.2018.11.028

[23] Jongwannasiri, C., Li, X. and Watanabe, S. (2013) Improvement of Thermal Stability and Tribological Performance of Diamond-Like Carbon Composite Thin Films. Materials Sciences and Applications, 4, 630-636. https://doi.org/10.4236/msa.2013.410077

[24] Wang, G., Kuang, X., Zhang, H., Zhu, C., Han, J., Zuo, H. and Ma, H. (2011) Silicon Nitride Gradient Film as the Underlayer of Ultra-Thin Tetrahedral Amorphous Carbon Overcoat for Magnetic Recording Slider. Materials Chemistry and Physics, 131, 127-131. https://doi.org/10.1016/j.matchemphys.2011.07.077

[25] Azzi, M., Amirault, P., Paquette, M., Klemberg-Sapieha, J.E. and Martinu, L. (2010) Corrosion Performance and Mechanical Stability of 316L/DLC Coating System: Role of Interlayers. Surface and Coatings Technology, 204, 3986-3994. https://doi.org/10.1016/j.surfcoat.2010.05.004

[26] Chin, H., Yoshida, S. and Watanabe, S. (2018) Tribological Behavior of Binary B-C Films Deposited by Sputtering-PBII Hybrid System. Materials Sciences and Applications, 9, 723-731. https://doi.org/10.4236/msa.2018.99052 